Article

\title{
Contingent Control and Wild Moments: Conducting Psychiatric Evaluations in the Home
}

\author{
Robert M. Emerson * and Melvin Pollner + \\ Department of Sociology, University of California, Los Angeles, CA 90095, USA; E-Mail: remerson@soc.ucla.edu \\ * Corresponding author \\ + Deceased
}

Submitted: 19 October 2018 | Accepted: 19 November 2018 | Published: 28 February 2018

\begin{abstract}
When social control and social service workers go into the field, into the "native habitat" of some problem, a variety of tacit structures and controls that mark office work with its standardized documents and formal meetings are weakened or absent entirely. As a result, compared to office settings, social control work in field settings tends to become open, contingent, unpredictable, and on occasion even wild. This article provides a strategic case study of the distinctive features of social control decision-making in the field, drawing on observations of field work by psychiatric emergency teams (PET) from the 1970s. PET typically went to the homes of psychiatrically-troubled persons in order to conduct evaluations for involuntary mental hospitalization. This article will analyze the varied, situationally-sensitive practices these workers adopted to evaluate such patients in their own homes.
\end{abstract}

\section{Keywords}

clientization; field psychiatry; frontline decision-making; social control; home visits

\section{Issue}

This article is part of the issue "'Producing People' in Documents and Meetings in Human Service Organizations", edited by Malin Åkerström (Lund University, Sweden) and Katarina Jacobsson (Lund University, Sweden).

(C) 2019 by the authors; licensee Cogitatio (Lisbon, Portugal). This article is licensed under a Creative Commons Attribution 4.0 International License (CC BY).

\section{Introduction}

This article will analyze the distinctive features of doing psychiatry in home and field settings, focusing on a historically remote but relatively unalloyed form of psychiatric homework - that practiced by psychiatric emergency teams (PET) in private homes in the early 1970 s. In California, PET was created in response to the closing of the large state mental hospitals and the turn toward community mental health. Mental health centers in Los Angeles organized two-person psychiatric teams to go out into the community in response to citizen calls for crisis intervention and mental hospital evaluation. These units functioned as psychiatric gatekeepers under California's Lanterman-Petris-Short (LPS) Act passed in 1969. Following a request from some family member or other private party, teams went out to the homes of those reported as psychiatrically disturbed to conduct evaluations for possible hospitalization. PET and the police were the only field agencies authorized to order involuntary hospitalization. In the home, the team would try to talk with the "candidate patient" (see Holstein, 1993) about current problems or the allegations of misconduct that had been reported. On deciding that hospitalization was necessary, the teams called an ambulance service to restrain and transport unwilling and sometimes violently resistant patients. Hospitalized patients could be then held for 14 days at the discretion of hospital staff.

Although our observations of these psychiatric teams were collected over four decades ago, ${ }^{1}$ PET decisionmaking highlights a number of extreme features of field

\footnotetext{
${ }^{1}$ Los Angeles County Department of Mental Health continues to field mobile "crisis evaluation teams" with the authority to initiate involuntary hospitalization (see dmh.lacounty.gov).
} 
and homework and thus provides a particularly instructive case study of the processes of clientization (Gubrium \& Järvinen, 2014) and social control carried in non-office settings. In what follows, we will analyze the distinctive contingencies of decision-making grounded in homes and other non-institutional settings, thrown into high relief by PET interventions.

\section{Frontline Decision-Making in Field Settings}

A number of comparative analyses of the work of social service and social control institutions have analyzed the decision-making activities of agents who have regular, direct interaction with those being serviced or processed. Termed "front-line bureaucrats" (Smith, 1965), "streetlevel bureaucrats" (Lipsky, 1980), "frontline" workers or officials (Dingwall, Eekelaar, \& Murray, 1983). These agents include:

[T]eachers, police officers and other law enforcement personnel, social workers, judges, public lawyers and other court officers, health workers, and many other public employees who grant access to government programs and provide service within them. (Lipsky, 1980, pp. 3-4)

Direct frontline contacts with clients create common work features, including broad discretion in applying general rules and policies to specific cases, persistent concern with husbanding and allocating time, energy and resources, and having to "deal with clients' personal reactions" to decisions affecting their fates (Lipsky, 1980, p. 9).

However, analyses of frontline social control have generally paid little attention to exactly where decisions are made (for recent exceptions see Hall, 2017; Ferguson, 2018). Yet different settings and contexts create fundamental variations in control and service encounters; in particular, critical differences mark interactions with clients and others that take place in an office or other institutional setting, and such encounters occurring in the field, often in "the native habitat of the problem" (Bittner, 1970, p. 40, emphasis added). Examples of the former include client contacts with courts, lawyers and prosecutors, with physicians in medical offices and hospital settings, with psychiatrists in clinical settings, and with correctional officers working on prison floors. Frontline decision-making in unofficial "native habitats" occurs on a variety of occasions: Citizen encounters with police patrol officers and traffic enforcers, in-home visits by probation and parole officers, child protection and social workers, medical home caregivers and hospice workers.

Frontline field work encounters in native habitats may occur in either public or private places. The former includes contacts in distinctly public spaces-most notably police patrol work on the streets-and in somewhat less open quasi-public settings-malls, restaurants, bars, and a variety of workplaces. In contrast, other occasions of frontline fieldwork unfold in private places legally authorized "to maintain their boundaries and determine their own interaction without interference from the outside" (Stinchcombe, 1963, p. 151). Such fieldwork occurs when probation and parole officers, social workers, child protection workers, and the police responding to calls involving domestic problems carry out their work in private homes or semi-private residential facilities (e.g., nursing homes, rehab programs, etc.).

This article will analyze frontline decision-making in private homes. Prior research suggests subtle but profound differences in decision-making in homes as opposed to office and other institutional settings (Ferguson, 2018). Consider the comprehensive study by Dingwall et al. (1983) on health visitors and child protection/neglect social workers in the UK in the early 1980s. While on occasion seeing clients in clinical settings, these workers regularly visited families with newborn children or where an issue of possible child abuse or neglect had been raised. Interpretative practices employed in the field contrasted with those characteristic of the officeand clinic-based medical practitioners and legal agents who dominated subsequent stages of child protection case processing. The former relied on "social evidence" to decide whether a particular child was abused or neglected and saw the children as "social objects" (Dingwall et al., 1983, pp. 55-78). In contrast, office-based child protection professionals relied on "clinical evidence" and constructed the children as "clinical objects" (Dingwall et al., 1983, pp. 31-54). Tensions between the practices and objects of fieldwork and office decision-making permeated the identification and processing of child protection cases.

Decision-making in home and other field settings face a number of distinctive contingencies and dilemmas. In the first place, working in the home loosens the chain of supervision to a much greater degree than ordinarily occurs in office work; such workers have greater mobility, more unaccountable time and hence more discretionary latitude in how they deal with cases compared to office workers. Second, in both home and field settings control agents frequently enter local environments they have not previously encountered and about which they know little or nothing. Agents working in private households in particular operate in terrains controlled by native habitants, in the process running up against particularistic social and living arrangements, in-situ constraints and demands, and complex multi-party relationships. Third, the stances of local parties toward official intervention may well turn out to be equivocal, indeterminate, or even directly resistant. As a result, both home and field decisionmakers may regularly encounter unpredictable, difficultto-control, even wild situations.

In the 21st century the frequency of decision-making in the homes of clients and patients may be increasing: many treatment and control institutions augment office contacts by sending personnel to the homes of those being treated or supervised. A number of recent stud- 
ies highlight social work outreach to the homeless on the streets (Hall, 2017) and the importance of home visits in working with problemed families (Ferguson, 2018). Similarly, while probation and parole supervision can be provided in office settings, regular efforts are made to visit clients in order to evaluate their current living situations and get more direct readings of their current adjustment (Paik, 2011). In medical practice nurses and physical therapists are routinely sent to the homes of recovering surgery patients and a wide variety of social welfare agencies send agents to evaluate or work with clients in their homes. As a result, low-income families with serious medical, mental health and legal problems may have official contact with multiple officials, many of whom frequently visit the home (Paik, 2017).

Parallel trends mark the mental health field. While much psychiatric practice still centers in institutional and office settings, outreach efforts directed toward the homeless, street addicts, and "runaways" are provided outside office contexts, often on the streets (e.g., Hall, 2017), but also in temporary residential facilities such as hostels and shelters (Farrell, Huff, MacDonald, Middlebro, \& Walsh, 2005; Goering, Wasylenki, Lindsay, Lemire, \& Rhodes, 1997). Programs emphasizing community psychiatry are keyed to outreach practices directed to local neighborhoods, streets and homes (e.g., Terkelsen \& McCarthy, 1994). Mental health clinics in the US cities provide crisis intervention through visits to field settings and a variety of innovative treatment programs, such as the Open Dialogue Approach originated in Finland, rely on mobile crisis intervention teams (Seikkula \& Olson, 2003).

\section{Two Case Studies of Psychiatric Intervention in the Homes of Patients}

We develop our analysis by examining two cases illustrating the dynamics of conducting psychiatric evaluations in the homes of candidate patients. ${ }^{2}$ These cases, involving women we call Tina Williams and Jo Sherman, were selected because they display features that highlight two significant attributes of PE teams' psychiatric homework. First, variations in how PET workers attended and responded to the local and contextual features of encountering patients in their homes. Second, the possibilities for wildness that such home evaluations could generate.

\subsection{Tina Williams}

PET received a call about a woman whose problemed behavior was recorded as follows: "Threatened neighbors, broke window, tried [to] hit caller when he asked question yesterday. Moved into building three weeks ago. Pounds on floor and hammers at night. Invites people in off street. Police there four [times] in last three days. Tells stories of things that [had] not happened".

The call was initiated by a neighbor identified as Alan, a driver from an ambulance service often used by PET to transport patients to mental hospitals. A team, led by a psychiatrist, Dr. Rogers, who had long experience in office practice before beginning to work with PET, and Cathy Collins, a public health nurse who frequently participated on mobile teams, was formed to respond to the call. Both team members were white. Rogers emphasized the reports of paranoid violence and insisted that the police be called to meet the team at the candidate patient's address.

Rogers and Collins, accompanied by one observer, drove to an apartment in a predominantly black innercity neighborhood; two white police officers and three black neighbors-Alan Crenshaw, his wife and a woman who lived on the first floor-were waiting outside. Alan began by explaining: "This woman [Tina Williams] moved in here. It hasn't been one month....From the first she was kind of weird". Crenshaw, noting that he was the apartment manager, described a number of trouble incidents involving Tina. Rogers, responding that "she sounds paranoid", cut off further talk; "Let's go see the woman".

All six of us walked up the stairs and gather in the hall outside one of the two second-floor units. Rogers knocked loudly a number of times, eventually eliciting a response: "Go away. Tina's not here. Her sister's here". Both the police and Rogers urged the speaker to open the door; one of the officers eventually shifted tactics to say that they wanted to come in to help Tina with her problem with the woman downstairs. Finally, Tina unlocked the door, saying only the police could come in. But Rogers, Collins and I followed the officers inside.

As we entered Tina retreated down the hall into a bedroom and sat on the bed, Rogers and the two cops standing in the doorway. A black woman in her 30s wearing a halter top and shorts, Tina complained to the police that Alan had held a gun on her and they should do something about it. But the police edged back into the hall, and Rogers moved forward: "I'm Dr. Rogers. I'd like to ask you a few questions". Tina correctly identified the day of the week and the month, but then added: "This don't make sense. This must be Alan. It must be Alan".

Rogers and Collins pressed Tina to come with them to a hospital for help. Tina equivocated, saying on the one hand "I will go with you if you want me to"; but on the other strongly objected: "Why y'all gonna put me in jail? Why are you holding me when it's the guy downstairs that did it? This is wrong! This is really wrong!" She raised the possibility of going to her sister's in Kansas City. But both team members insisted on the need to go to the hospital, and eventually Collins used the house phone to call a local mental hospital to confirm Tina's admission.

\footnotetext{
2 The authors personally conducted all the fieldwork for this project. In the fieldnotes that follow, direct quotations mark dialogue jotted into a notebook as the interaction proceeded. Entries without quotations are indirect quotations-paraphrases recalled from memory when full fieldnotes were written as soon as possible after leaving the field (see Emerson, Fretz, \& Shaw, 2011, pp. 63-66). The accounts provided here are selected summaries; additional fieldnote material will be provided in later analyses.
} 
As Tina heard this, she begged Rogers: "Don't take me to the hospital. Don't do that. Don't do that.... won't go to the hospital.... Why you gonna put me in the hospital?" Rogers: "It will help you feel better, so you can go to Kansas City, or to Tina's house, or wherever".

The psychiatric team and the police urged Tina to get dressed. She began to do so but broke away to go into the living room to call her mother-in-law in LA to ask about staying with her rather than going to the hospital. She talked on the phone for some minutes, but it was clear that her mother-in-law would not take her in. Back in her bedroom Tina again pleaded to be allowed to go to Kansas City or to her "momma's"; PET responded that she could do that after she was out of the hospital and feeling better.

Tina now had a dress on, and with urging from the police, put her shoes on, continuing to protest that what they should have done is take Alan's gun. When the phone rang, she went to the living room to answer it: "Hi. They're getting ready to take me to jail". Rogers and Collins: "No, no, to the hospital". It's her daughter, and she told her: "That nigger got me in all this trouble". After a few exchanges, Collins took over the phone and gave the caller the phone number of the mental hospital in order to contact Tina. (Collins later told Rogers that the caller was not her daughter but a friend). Finally, team members and the police ushered Tina down the stairs and into the police car for the trip to the hospital.

\subsection{Jo Sherman}

PET had been contacted several times by a man who reported that his wife was disturbed; she had moved into her own apartment, leaving him and their son. He had been unable to convince her to go to the hospital and wanted PET's assistance. Art, a white psychiatric social worker, and Bea, a black psych tech, arranged to meet him at the apartment where his wife had moved some ten days previously. The apartment was located a block off the Sunset Strip, an area marked by a number of bars and clubs and an active night life.

At the address we were met by a youth who asked if we had come to talk to Jo Sherman, and who then led us to \#6, a second-floor unit at the rear of the small apartment complex. The door to the apartment was open, and Mr. Sherman came out and briefly talked with Art, explaining that his wife had not been taking her medications because she thought that her doctor was against her, that he's a Nazi.

The four of us entered a one-room apartment (the son-Rickie, 9-sat down outside the open door) and found a white woman with long black hair (a wig, Bea later told me) in her early 30 s dressed in a loose yellow blouse and jeans, sitting on the bed with a blue blanket drawn around her shoulders. Bea introduced the team. The husband said something to his wife which I did not hear, and she responded with a loud tirade: Don't listen to him, he's a dope addict, he's a dupe, he's a criminal.
Art sat down on the floor facing her, and after explaining that we are from County Mental Health Services, continued: We really don't know what's going on here. We got a call and we came out and we wanted to see what we can do to help. Like are you having problems? To which Jo responded: "No. No problems". Art: "Well, we heard that you disappeared". Jo: "I left my husband". Art: "How have you been getting by? How have you been supporting yourself?" Jo: "I got ATD [Aid to the Disabled])". "Is that enough to live on?" "Yes, I don't need much money".

Jo then shifted back to her husband, who had been sitting in chair across the room: "He's trying to kill me....The mother's trying to kill me. He's the ringleader of the Communists. But I'm not worried, I can take care of it....I'm with intelligence, my father works for the State Dept. and they know what's going on". Art asked whether she had seen her doctor. "No. He's a dope addict and he's with the Nazi Party". Art pressed her to come in to the clinic to get more medicine, but Jo declined and continued to accuse her husband.

Art, Bea and I moved out on to the balcony to discuss how to proceed, leaving Mr. S in the apartment with his wife. Art and Bea conferred, the former commenting: "She's pretty out of it, she's pretty angry about it", the latter agreeing. They decided to call an ambulance to have her hospitalized. But when the husband came out the door, we heard Jo yelling: "Get the son of bitch out of here!" A scuffle broke out at the doorway, Art later reporting that the husband had slugged her. Jo shouted: "You get out, you Communist leader", and then threatened to call the police to remove him, PET and sociologist from her apartment. She confronted Art: "You can't take me away either". Art replied: "We didn't say we werewe ain't gonna take you away". "We'd like to help you here". Jo: "Help me then". Bea began talking gently with Jo and moved into the apartment with her; I left with Art and the husband to find a phone to call the ambulance.

On our way out, Art suggested trying to use the phone of the apartment manager, and when the latter answered her door and agreed to let him use her phone, Art asked about Jo: "How's she been?" "She's quiet. Just very quiet and no problems but haven't really seen her leave the building. It's kind of, like, she's on a downer". We then visited the owner who lived in the unit, who also described Ms. S as "very quiet and very nice". "No one's complained?" "No one's complained". She noticed that she had the place "all straightened up" and that had impressed her. Again, she seemed "very sweet, very nice".

At this point Art had abandoned the plan to call an ambulance to hospitalize Jo and indicated that he would talk to her about medications and ask the manager and owner to keep an eye on her. Insisting that the husband stay outside, Art had a long talk to Jo, focusing on the medications prescribed by a psychiatrist she had seen recently. Art emphasized several times: "We don't want to hospitalize you; if you will just take your meds we won't have to hospitalize you". He asked Jo to take her 
meds then and there (her son had reported that she has flushed pills down the toilet), but she refused, saying they make her sleepy; she also explained that she had flushed pills given her by another psychiatrist down the toilet because they had not been in a prescription bottle. Eventually Art accepted her promise to take her prescribed meds that evening and said that he would check back with her in a day or two.

Despite racial and neighborhood differences, these cases reveal a number of similar features: Women living alone in their own apartments, acting in ways that psychiatric workers viewed as unquestionably paranoid but interspersed with lucid exchanges, and displaying deep anger and profound suspicion toward the parties who had sought intervention. But the teams ultimately took very different actions, in one case hospitalizing the patient over her strong objections, in the second avoiding hospitalization by patching together an ad hoc plan to leave the patient in her home. In what follows we want to examine the generic processes marking these homebased psychiatric evaluations and efforts at clientization.

\section{The Problematics of Psychiatric Homework}

PET workers were acutely aware of the difficulties of conducting psychiatric evaluations in others' native habitats: not only did they not control the space in which the evaluation was to take place, but they also lacked immediate access to the full range of therapeutic responses available in their own clinic. Indeed, many community mental health center staff members refused go out to the field at all for these reasons. And the standard response of those who routinely did home visits was to urge even overtly resistant patients to come into the clinic for immediate help. Art explained the rationale for this default position on the drive back to the clinic after a home visit:

[The office provides] a whole new ballgame.... Once you get them in the office there is a whole different tone.....It's our territory. We can be more aggressive, and they have to respond. We'll be able to work directly to make arrangements.

Thus, workers relied on a set of distinctive practices to conduct home evaluations: gaining and maintaining contact with often uncommitted patients; reading the local context; managing the presence of others at the local scene; dealing with divergent local concerns; and balancing the sometimes conflicting implications of psychological disturbance and practical manageability in home situations.

\subsection{Gaining and Maintaining Access to Candidate Patients in the Home}

PET confronted the problematics of clientization in stark form: lacking assured access to the patient, even gaining entrée to the home could pose a formidable problem.
Workers routinely turned to the caller, particularly a family member, to gain access to the patient, often successfully. But if the caller did not live with or had an antagonistic relationship with the patient, the result could be overt and hostile resistance, as occurred in the case of Jo Sherman. Similarly, Tina Williams resisted repeated requests to open the door, stymying the team for some 15 or 20 minutes until taken in by a ruse initiated by the police.

In initially encountering candidate patients, workers typically explained who they were and proposing that their presence was an effort to "help" with any "personal problems", as with Jo Sherman. When Jo rejected this initial offer, insisting that she had "no problems", Art pressed her: "We're from the clinic, we'd like to get you some more medicine, and we'd like to help you there. Would you come to the clinic?"

Similarly, Rogers had introduced himself to Tina Williams as a doctor (not a psychiatrist), and elaborated this stance once inside the apartment:

"I'm Dr. Rogers. I'd like to ask you a few questions. Could you tell me what day it is?" Tina initially responds "Now, what is all this for?", then correctly identifies the current day and month. When Rogers responds "A lot of people don't know that. I'm not trying to trick you", Tina insists: "You must be....This don't make sense. This must be Alan. It must be Alan".

Here the psychiatrist moved immediately from his minimal self-introduction to ask two questions, checking appropriate psychological orientation. Tina expressed confusion but quickly provided the correct answers, reluctantly cooperating with the team while conveying deep distrust of the process as something initiated by the complainant- "this must be Alan".

Finally, once PET had entered the home, team members worked to maintain that contact. Doing so could be problematic, since patients often exercised physical and interactional autonomy of a sort severely restricted in office settings. Team members responded in several ways to this autonomy of movement. First, workers tried to preempt the possibilities of patient movement; for example, on entering, PET and the police maneuvered Tina into her bedroom, conducting most of their evaluation while standing in and essentially blocking the doorway. Second, workers took care to stay physically close to patients; they moved with Tina to the balcony door, the hall, and the living room. Similarly, when leaving to call an ambulance, one team member stayed in the apartment, assuring both continuing contact and reentry when necessary.

In sum, in offering "help" to a patient, PET sought to structure in-home interaction as a "therapeutic" encounter. But efforts to entice patients to cooperate often met with evasion, denial and resistance. Nonetheless workers persisted, seeking cues about patients' living situations and mental states, then circling back to again try to elicit cooperation. 


\subsection{Attending to Local Context}

Entering home settings provided the PET with direct and detailed evidence of the patient's routine behaviors, daily life and mental condition. Workers drew heavily on two features of the observed home context-its material features and the relational contours of the patient's living situation.

Initially, team members might read the home setting itself-neighborhood, home furnishings, cleanliness, order, messiness, smells, etc. - as a coded text for what life in that household was like. Jo's neat and orderly apartment indicated a person able to move in and successfully set up a separate household. Tina's disorderly rooms evidenced troubled and disorganized living circumstances.

Coming into the home also gave the team direct access to the relational parameters of the patient's living situation. PET workers tended to encounter other participants in the household environment-parents, spouses, relatives, children, neighbors, landlords-and to attend to their relations with the patient. If family members in the home seemed genuinely concerned about the patient's welfare and had some sort of working relationship, team members could draw on this supportive tie to learn about recurring problems.

Being on the scene put PET workers into direct contact with a complainant pushing for an outcomehospitalization - that was as yet undecided. Whereas in office encounters complainants had at least partially succeeded in their complaint (in that a psychiatrist had agreed to see the patient), callers to PET had to actively work to convince the team that hospitalization in these particular circumstances was necessary. To do so, complainants tended to elaborate and upgrade their initial accounts of troubling acts committed by the patient. PET workers' first encounter with the caller complaining about Tina Williams included an elaborated account not only of details of a number of seriously irrational actions by the patient, but also highlighted threats of violence.

In sum, being on the scene of reported troubles provided psychiatric workers with more detailed insights into the troubled situation than would be available in office encounters.

\subsection{Doing Psychiatric Assessments in the Presence of Local Others}

PET usually saw patients at home in the presence of their significant (and sometimes not so significant) others. For many purposes the presence of others offered useful resources-parties to fill in relevant background information, to pressure the patient to respond to workers' proposals, and to provide accounts of incidents the latter refused to acknowledge. But the presence of these others also meant that team members had to conduct exchanges with the patient that could be overheard and monitored by parties often not content to sit back and let them control the encounter. In these ways, home evalu- ations could become multi-party events raising complex management problems.

Team members employed a variety of strategies to elicit the specifics of one person's trouble while being closely monitored by others with a stake in that trouble. Initially, workers made special effort to talk to callers and other concerned parties before making direct contact with the patient, as in both the cases considered here. Once in the presence of the patient, they might ask the caller to withdraw, or separate the parties. Or when others were present, team members might focus their attention and questions specifically on the patient, discouraging others from commenting on or intervening in these exchanges.

Relatedly, PET workers frequently relied on onesided communications to manage the parties to the call. Thus, while after his first discussion with Jo, Art informed Mr. Sherman outside the apartment that he was going to arrange hospitalization for his wife, he kept this (tentative) decision from the patient. Conversely, staff might privately confer with and advise the patient not to convey potentially incendiary personal information to the caller, as in this instance:

With her husband sent outside the apartment while she spoke with Art and Bea, Jo made a reference to her "boyfriends". Both team members were emphatic that that aspect of her life didn't concern [them] and that they wouldn't bring that up in front of her husband.

In managing such "secrets" workers expressed and tried to create alignment-however partial and temporarywith one or the other party.

In general, the problems arising from multiple parties were exacerbated when the team encountered in-house troubles marked by strong disagreement and heated opposition between the caller and the person called about. In these circumstances, workers had to give constant attention to managing these conflicting stances and demands.

\subsection{Managing Different and Opposing Concerns}

The presence of an active complainant on the scene increased the possibilities of encountering strongly opposing stances toward the problem. Having selected a call for home visit, team members had accorded tacit validity to the initial complaint; the situation as recounted by the caller merited at least first-hand evaluation (Emerson, 2015 , pp. 234-235). Thus, in both the cases we are considering, evaluators came to the situation pre-aligned with the caller, having accepted the general contours of the problem as reported by the complainant and as initially confirmed at the site.

Calling in the police to support home entry reinforced pre-alignment with the complainant and often escalated the possibility of patient resistance. While Rogers had 
insisted that that the police be present as a condition for his going out on the Tina Williams call, most workers were extremely reluctant to do so, fearing that police presence might destroy any possibility of developing trust with the patient.

Once on the scene, team members often approached the patient in ways that reflected this pre-alignment, as in Rogers' first questions to Tina seeking to test her psychological orientation. And PET might sustain this alignment with the caller throughout the evaluation, even in the face of persistent counter-claims from the patient. Furthermore, throughout the encounter both team members continued to urge Tina to go to the mental hospital, disregarding her pleas that she was being threatened by Alan and his wife, was not crazy, and did not want to go to "jail". The psychiatrist pushed hospitalization not by challenging Tina's claims of having been victimized by Alan and his wife, but by using her "paranoid" beliefs to argue that hospitalization was a solution that would allow her to get away from Alan and his threats. Thus, despite Tina's insistence right from the start that the apartment manager had called because of personal ill-will, Rogers held steadily to courses of inquiry and action that presumed her mental instability.

In other situations, sensitive to signs of hostility between family members and the proposed patient, workers might begin to take actions that signaled a shift from alignment with the caller. As home evaluations unfolded, the direction of team members' questions could reveal staff's emerging take on the situation and their preferred line of response. Thus, Art's interest in talking to Jo's apartment manager and landlord, and his positive reaction to favorable reports about her behavior from these local sources, signaled a shift in alignment made explicit when he abandoned any attempt to use a phone to call an ambulance. But indications of such a shift in alignment could elicit vigorous protest by the caller. Workers were well aware of this possibility and tried to anticipate and minimize likely objections from complainants.

In sum, conducting psychological evaluations in the home often confronted psychiatric teams directly with two parties with strongly opposed claims about what was going on and what should be done about it. Workers could take up different alignments between these parties, but always had to anticipate and attempt to manage the reactions their observable actions were likely to elicit.

\subsection{Assessing Symptoms and Tenability In-Situ}

PET weighed two considerations in evaluating patients for hospitalization: the severity of the patients' mental disturbance, and the tenability of patients' living situations. The tension between these concerns arose in part from the LPS legislation that authorized involuntary hospitalization only when mental illness affected a person's actual living circumstances, creating danger to self or danger to others. While workers characterized many pa- tients as mentally ill, they could still conclude that they were "not LPS" and hence should not be hospitalized. Indeed, on occasion some viewed some patients as "really crazy" but nonetheless functioning in circumstances that were sufficiently manageable to avoid hospitalization (Emerson, 1989).

Encountering patients in their own homes allowed PET to witness directly variations in symptomatic behavior and the stability of living conditions. With regard to the former, in the home, fieldworkers could observe the patient interacting in vivo with a wider range of others than would have been seen in office settings. With both Tina Williams and Jo Sherman, team members drew on observations of naturally occurring interactions between the patient and others to come to nuanced assessments of mental condition-hallucinatory and paranoid, yes, but in relationally specific and thus distinctly occasioned ways. Jo Sherman was classically paranoid in her denunciation of her husband- "He's a dupe, a dope addict, a ring leader of the communists, trying to kill me!"but she talked calmly and generally coherently about her current situation. Later her landlords' favorable reports on their encounters with her reinforced the team's sense that her delusional behavior was tied centrally to her relations with her husband.

Workers were also in position to make direct assessments of the manageability of patients' living situations. On the one hand, going into the home led staff to draw very different conclusions from Tina's disordered rooms as opposed to Jo's sparse but orderly living area. On the other hand, reports from family members, neighbors and landlords could fundamentally shape their sense of the tenability of patients' living situations. Encounters with these others were often opportunistic: Art decided to drop in on the apartment manager in part as a practical convenience-to avoid delay and uncertainty in having to walk down to the corner to find a pay phone to call an ambulance. But he immediately picked up her favorable attitude toward a woman who moments earlier had been screaming wildly paranoid accusations.

In sum, these features of psychiatric homeworkuncertain physical and therapeutic access to the patient, encountering the patient within a distinctive local context, often with family and others in attendance, managing the sometimes conflicting demands of these parties while at the same time having to weigh the salience of both psychiatric symptomology and practical living circumstances-introduced wide variation and uncertainty into these psychiatric evaluations. These uncertainties could lead to distinctively unpredictable, emotionally and physically wild exchanges.

\section{Wildness in the Psychiatric Homework}

Several features made PET interventions in the homes of those identified as psychiatric problems highly unpredictable, fluid and volatile. First, right from knocking on the door, workers could not predict what would happen 
when they confronted the person called about; indeed, most of these persons first learned that they were candidate patients facing possible hospitalization at this moment. As a result, home evaluations could immediately become hostile, messy and explosive.

Second, conducting psychiatric evaluations in home settings led to direct and often emotionally confrontational encounters between complainants and proposed patients. As noted, often both parties were on the scene and urgently insistent that the team recognize their concerns and take action on their behalf. These face-to-face confrontations could become heated and ugly.

Third, PET's decisions on outcome were fluid and yet ultimately observable by both parties. At the point persons realized they were being hospitalized despite their objections they might respond angrily. Or the complainant might explode on realizing that the team was not going to hospitalize the proposed patient, as when, Mr. Sherman learned that Art was going to leave Jo in her home:

Mr. S objects and becomes progressively more angry, mentioning how he is stuck at home left to watch the children. At one point he argues: "I'm afraid if she stays in the apartment that she will kill herself. She should go, I'm telling you, for her own good". Art reasserted the plan: "Well, we want to try it this way first. If we can get her to take her medicine, we think that will do it". Mr. S responded: "Well, if she does kill herself then it's gonna be your responsibility...not mine". Art: "Yeah, that's the way it will be. It's our decision".

Emergent shifts in alignment could not only change the anticipated hospitalization outcome but could also transform workers' understandings of the moral character of the parties involved. For example, in deciding not to hospitalize Jo Sherman, Art not only legitimized her insistence that she was separating from her husband, but also recast her husband's pressure to hospitalize as an exploitative demand by an overly controlling spouse. Jo's report after her husband left that he had a gun in his car confirmed this emerging appraisal of his anger and potential for violence.

In contrast, in other cases, PET validated the initial claims of callers, dismissing the legitimacy of counterclaims. With Tina Williams, the team remained aligned with the complainant, giving no credence to her alternative version of the apartment manager's actions. Hospitalization on a short-term basis was seen as the appropriate and necessary response to a patient with a serious psychological disturbance living in highly combustible circumstances.

\section{Conclusion}

In her classic research on life-and-death decisions in intensive care units for newborn infants, Anspach (1987, p. 229) emphasized that different staff work practices produced distinctly different "ecologies of knowledge" of these cases and their likely outcomes. She showed how physicians and nurses develop conflicting conceptions of the future of the infants.

[R]esidents, whose contact with infants is limited and technologically focused, base their prognostic assessments largely on 'hard' data, acquired by means of sophisticated measurement instruments (technological cues)....[Nurses], unlike the physicians, sustain continuous contact with infants and derive much of their work satisfaction from interaction with infants who are medically and socially responsive (interactive cues).

In these ways, routine work experiences in diagnosis and care made salient different aspects and dimensions of these infants. While in many cases interactive contacts led nurses to hold more optimistic prognoses than physicians, they were more pessimistic with infants "who are unresponsive, pose behavioral problems, or require chronic care" (Anspach, 1987, p. 229).

Similarly, we suggest that PET's homework practices gave rise to distinctive working ecologies of knowledge that differ significantly from those that mark psychiatric decision-making based in office settings. In the following we draw upon this analysis of PET home practices to identify features of field-based ecologies of knowledge more broadly. In so doing we will also consider how these practices suggest contrasting but often taken-forgranted features of office- and institution-based frontline decision-making.

\subsection{Clientization on the Spot}

Decision-makers in a variety of other field and home situations regularly encounter problematic attitudes and open resistance from those whose fates are being decided; as a result, intervention often centers on negotiating some degree of basic cooperation from the proposed client.

In contrast, clients or patients coming to an office setting thereby display at least some initial willingness to cooperate with frontline staff. By the time such an individual arrives at the hospital or clinic and despite whatever feelings of anger and frustration he may have with regard to his plight, he has been exposed to the fact that others feel he is in need of psychiatric care.

In this sense the psychiatric encounter within the office or institution occurs at the end of a chain of interactional pre-processing which at the very least alerts individuals to their status as someone subject to psychiatric scrutiny (Goffman, 1961). Similar pre-processing marks many other frontline office encounters, including those occurring in ERs, medical clinics, welfare offices, officebased probation and parole supervision, and criminal and civil courts. 


\subsection{Using and Managing Local Material and Interpersonal Environments}

When social control agents enter a home, they often rely on what they observed of the material and interpersonal environments of candidate patients (Ferguson, 2018). They may note the state of the property and its furnishings, of occupants' clothing and self-care. They may also observe the relationships between various parties.

In contrast, office-based frontline workers have no direct access to relevant local environments, instead basing assessments heavily upon in-office talk and demeanor and upon written records and reports. In general, then, lack of first-hand contact with clients' actual life circumstances in office-based frontline encounters will lead to elaborate interpretive practices for making inferences from institutionally-occasioned talk, appearance and demeanor, from the informal reports of complainants and involved others, and from a variety of official records and evaluations.

\subsection{Decision-Making in the Presence of Local Others}

In field and home settings frontline decision-making is observed not just by "established members of [the] work organization" (Goffman, 1961, p. 324), but also by local and/or outside others. Workers making such publicly observable decisions experience distinctive interactional and management problems; indeed, "the problem of facing the public and of controlling it is sufficiently central to merit treating together all who experience it" (Goffman, 1961, p. 324). In open public settings like the streets, frontline decision-making may attract large audiences. Anticipating and dealing with such audiences is a central concern in both ambulance and police work (Metz, 1981, pp. 144-154; Moskos, 2008). Similarly, a variety of local parties, particularly family members, routinely observed many PET home evaluations.

In contrast, frontline work in office and institutional settings relies on a variety of procedures to limit the access and control the behavior both of the general public and of those directly involved with the client and his/her troubles. Individual appointments, rules about privacy and confidentiality, worker control of office space and of the movement of clients and outsiders, and the ability to put off decisions until some later occasion, allow many actions to be taken behind closed doors and communicated to outside audiences in controlled and limited ways.

\subsection{Encountering Strongly Expressed, Conflicting Demands}

Going into field and home settings may confront frontline workers with parties with strongly opposed claims about what should be done. Indeed, trouble in homes and on the streets leading to outside intervention may be particularly "hot", involving parties consumed by out- rage, festering anger, and longstanding grudges. Frontline workers can of course take up different alignments between these parties, coming to side with one or another, or trying to establish some sort of balance between their positions. But they always have to be aware of and attempt to manage these competing demands.

In contrast, office settings provide a variety of resources to separate and defuse conflicting parties. Complainants may not need to be physically present for many instances, as in mental hospital wards and residential treatment programs; opposed parties may be seen privately or sequentially, and direct confrontations may be muted or avoided altogether with the involvement of attorneys or spokespersons; in court proceedings and mediation sessions, direct exchanges between opposing parties may be closely monitored and supervised.

\subsection{Reacting to Unpredictable, Emergent Situational Contingencies}

Decision-making in office and institutional settings is relatively constrained. Hierarchical supervision tends to be immediate, and unexpected, non-routine exchanges are organizationally visible. The weight of "like cases" and accountable precedents loom large. The salience of local contingencies is restricted, and the range of remedial possibilities is conventionalized.

In contrast, going into indigenous settings confronts fieldworkers with a wide array of contingencies and uncertainties. Indeed, field encounters and home visits provide and demand skillful practice relying on "creativity, craft and improvisation" in order to manage interactions with clients and their families (Ferguson, 2018, p. 67).

Field decision-making is often highly contingent upon specific contexts and unique circumstances. Being on the scene and directly encountering the unique features of local situations promotes fieldworker sensitivities to practical, pragmatic responses, reducing the relevance of formal, rule-based actions. Broad discretion and limited effective supervision allow fieldworkers take matters into their own hands to respond in grounded but sometimes unorthodox ways that take into account immediate circumstances and real concerns. Moreover, such decision-making can take on a subtle, self-consciously recursive character, with fieldworkers becoming particularly sensitive to what others do in response to their presence, overtures, and suggestions, thereby elaborating their sense of what could be done or what might have to be done.

\section{Acknowledgments}

This article evolved from literally years of work with my colleague and friend Mel Pollner. I hope that this version of our earlier writings captures Mel's concerns and insights into these processes. I also want to thank the following for comments and feedback on more recent drafts of this article: Ginger Emerson, Jack Katz, Leslie 
Paik, Robert Dingwall, Carol Warren, Malin Åkerström, David Wästerfors and Katarina Jacobsson.

\section{Conflict of Interests}

The authors declare no conflict of interests.

\section{References}

Anspach, R. R. (1987). Prognostic conflict in life-anddeath decisions: The organization as an ecology of knowledge. Journal of Health and Social Behavior, 28, 215-231.

Bittner, E. (1970). The functions of the police in modern society. Washington, DC: National Institute of Mental Health.

Dingwall, R., Eekelaar, J. M., \& Murray, T. (1983). The protection of children: State intervention and family life. Oxford: Basil Blackwell.

Emerson, R. M. (1989). Tenability and troubles: The construction of accommodative relations by psychiatric emergency teams. In G. Miller \& J. A. Holstein (Eds.), Perspectives on social problems: A research annual (Vol. 1, pp. 215-237). Greenwich, CT: JAI Press.

Emerson, R. M. (2015). Everyday troubles: The micropolitics of interpersonal conflict. Chicago, IL: University of Chicago Press.

Emerson, R. M., Fretz, R. I., \& Shaw, L. L. (2011). Writing ethnographic fieldnotes (2nd ed.). Chicago, IL: University of Chicago Press.

Farrell, S. J., Huff, J., MacDonald, S.-A, Middlebro, A., \& Walsh, S. (2005). Taking it to the street: A psychiatric outreach service in Canada. Community Mental Health Journal, 41(6), 737-746.

Ferguson, H. (2018). Making home visits: Creativity and the embodied practices of home visiting in social work and child protection. Qualitative Social Work, 17(1), 65-80.

Goering, P., Wasylenki, D., Lindsay, S., Lemire, D., \& Rhodes, A. (1997). Process and outcome in a hostel outreach program for homeless clients with severe mental illness. American Journal of Orthopsychiatry, 67(4), 607-617.

Goffman, E. (1961). Asylums. Garden City, NY: Doubleday.

Gubrium, J. F., \& Järvinen, M. (2014). Troubles, problems, and clientization. In J. F. Gubrium \& M. Järvinen (Eds.), Turning troubles into problems: Clientization in human services (pp. 1-14). London: Routledge.

Hall, T. (2017). Footwork: Urban patrol and the modern city. Chicago, IL: University of Chicago Press.

Holstein, J. A. (1993). Court-ordered insanity: Interpretive practice and involuntary commitment. New York, NY: Aldine de Gruyter.

Lipsky, M. (1980). Street-level bureaucracy: Dilemmas of the individual in public services. New York, NY: Russell Sage.

Metz, D. L. (1981). Running hot: Structure and stress in ambulance work. Cambridge, MA: Abt Books.

Moskos, P. (2008). Cop in the hood: My year policing Baltimore's eastern district. Princeton, NJ: Princeton University Press.

Paik, L. (2011). Discretionary justice: Looking inside a juvenile drug court. New Brunswick, NJ: Rutgers University Press.

Paik, L. (2017). Family illness' influence on parental involvement in adolescent chronic illness work. Manuscript in preparation.

Seikkula, J., \& Olson, M. E. (2003). The open dialogue approach to acute psychosis: Its poetics and micropolitics. Family Process, 42(3), 403-418.

Smith, D. E. (1965). Front-line organization of the state mental hospital. Administrative Science Quarterly, 10, 381-399.

Stinchcombe, A. L. (1963). Institutions of privacy in the determination of police administrative practice. American Journal of Sociology, 69, 150-160.

Terkelsen, K. G., \& McCarthy, R. H. (1994). Home visits in the era of cost containment. Community Mental Health Journal, 30(3), 297-305.

\section{About the Authors}

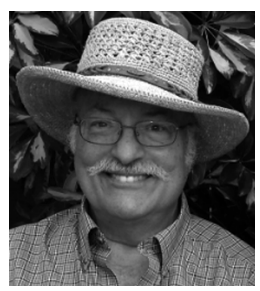

Robert M. Emerson is Professor Emeritus of Sociology at the University of California, Los Angeles. With Rachel Fretz and Linda Shaw, he co-authored Writing Ethnographic Fieldnotes (2011, 2nd ed.) and edited Contemporary Field Research: Perspectives and Formulations (2011, 2nd ed.). His substantive research examines indigenous and official processing of "trouble". It includes Everyday Troubles; The Micro-Politics of Interpersonal Conflict (2015, University of Chicago Press) and an in-progress collection of articles on official social control decision-making.



Melvin Pollner (1940-2007) was Professor of Sociology at the University of California, Los Angeles. His research employed both ethnomethodological and ethnographic approaches to analyze taken-forgranted processes of social life. In Mundane Reason (1987) and other writings, he examined how everyday reality - the ordinarily unquestioned conviction of "an 'out there', 'public' or 'objective' world" - is produced and sustained in ordinary interaction. 